\title{
El imaginario urbano del miedo en Latinoamérica: evidencias de estudios en Salvador de Bahía, Brasil, y Monterrey, México
}

\author{
Javier Alonso Gómez Dávila ${ }^{1}$ y \\ Rafael de Aguiar Arantes ${ }^{2}$
}

Fecha de recepción: 7 de octubre de 2015

Fecha de aprobación: 7 de marzo de 2016

\begin{abstract}
Resumen
Es innegable la importancia y la fuerza que el estudio de los imaginarios urbanos ha cobrado en los últimos años en las disciplinas espaciales, incluyendo la sociología urbana. Este trabajo analiza el origen, los significados y las consecuencias de uno de los imaginarios urbanos más latentes y poderosos en las ciudades latinoamericanas: el imaginario del miedo, el cual, con su mezcla de violencia real y percepción subjetiva de la sociedad, se ha convertido en la forma de habitar de la ciudad contemporánea latinoamericana, volviéndola un espacio de miedo e inseguridad, situación potencializada por el mercado inmobiliario y los medios de comunicación. Este trabajo toma como casos de estudio las ciudades de Salvador de Bahía, en Brasil, y Monterrey, en México, para analizar las manifestaciones sociales y urbanísticas de este imaginario, encontrando que el imaginario del miedo no es solamente un miedo a la violencia e inseguridad, sino también a mezclarse con el otro, una negación de la heterogeneidad, la diversidad y la sociabilidad que siempre han caracterizado a las ciudades, provocando así manifestaciones de aislamiento y segregación arquitectónicas, que hacen cada vez más difícil alcanzar un concepto de sustentabilidad urbana real.
\end{abstract}

Palabras clave: imaginarios sociales, miedo, segregación, América Latina.

Arquitecto, Doctor en Arquitectura y Asuntos Urbanos por la Universidad Autónoma de Nuevo León (UANL). Investigador sobre temas de sustentabilidad y justicia urbana en las ciudades latinoamericanas. E-mail: arqjaviergomez@gmail. com. (52) 811100-1291/811216-6929.

2 Sociólogo, Maestro y postulante a Doctor en Ciencias Sociales por la Universidad Federal de Bahía/Brasil. Investigador asistente del Observatorio de las Metrópolis, núcleo Salvador de Bahía. CAPES Foundation, Ministry of Education of Brazil, Brasília - DF 70040-020, Proceso: 99999.003883/2014-00 Brazil. E-mail: rafaelarantes13@gmail.com. (55) (71) 3535-1746/ 8845-9514. 


\title{
The Latin-American urban imaginary of fear: evidence from studies in Salvador, Brazil, and Monterrey, Mexico
}

\begin{abstract}
The importance and strength that the study of urban imaginary has gained in recent years in space disciplines is undeniable, including urban sociology. This paper analyzes the origin, meaning and consequences of one of the most latent and powerful urban imaginary in Latin American cities: the imagination of fear, which, with a mix of real violence and subjective perception of society, has become the way of living of Latin American contemporary city, as a place of fear and insecurity, a situation potentiated by the housing market and the media. This work takes cities of Salvador de Bahia in Brazil and Monterrey, Mexico, as case studies to analyze social and urban manifestations of this imaginary, finding that the imaginary of fear is not just about violence and insecurity but also about relating with others, a denial of heterogeneity, diversity and sociability that have always characterized the cities, causing manifestations of insulation and architectural segregation. This makes that reaching a concept of real urban sustainability is increasingly difficult.
\end{abstract}

Keywords: social imaginary, fear, segregation, Latin America.

\section{O imaginário urbano do medo na América Latina: evidências de estudos em Salvador de Bahía, Brasil e Monterrey, México}

\begin{abstract}
Resumo
É inegável a importância e força que o estudo dos imaginários urbanos tem ganhado nos últimos anos nas disciplinas espaciais, incluindo a sociologia urbana. Este trabalho analisa a origem, os significados e as consequências de um dos imaginários urbanos mais latentes e poderosos nas cidades latino-americanas: o imaginário do medo, o qual se mistura de violência real e a percepção subjetiva da sociedade, tornou-se forma de viver a cidade contemporânea latino-americana, volvendo-se num espaço de medo e insegurança, situação potenciada pelo mercado imobiliário e da mídia. Este trabalho tem como estudos de caso as cidades de Salvador de Bahia, no Brasil, e Monterrey, no México, para analisar manifestações sociais e urbanas deste imaginário, encontrando que o imaginário do medo não é apenas um medo de violência e insegurança, mas também, se misturar com outro, uma negação da heterogeneidade, a diversidade e sociabilidade que sempre tem caracterizado as cidades, causando manifestações de isolamento e segregação da arquitetura, o que torna cada vez mais difícil de lograr um conceito de sustentabilidade urbano real.
\end{abstract}

Palavras - chave: imaginários sociais, medo, segregação, América Latina. 


\section{Introducción}

El presente trabajo analiza uno de los elementos que se encuentra más presente en el imaginario urbano actual de las ciudades latinoamericanas: el miedo. Como será detallado en la siguiente sección, los imaginarios forman parte de la subjetividad individual y colectiva y están relacionados con la facultad de simbolización humana. Ellos crean imágenes actuantes en la vida de la gente, imágenes guías que conducen procesos y representan realidades materiales y subjetivas, haciendo emerger sus miedos, deseos, sentimientos y esperanzas. En las ciudades, esta capacidad es ampliada por el exceso de estímulos visuales existentes en sus espacios tan complejos (Simmel, 1979). Estudiar imaginarios es, pues, "reconstruir la visión de la ciudad que impregna la mente de sus habitantes" (Hiernaux, 2007, p. 24).

Conforme se planteará a lo largo del artículo, la imagen de una ciudad peligrosa, llena de amenazas y de la cual es necesario protegerse, es una de las que tienen más fuerza en la vida actual de las ciudades latinoamericanas. Este imaginario está involucrado con un conjunto de transformaciones sociales y urbanas; entre ellas, la ampliación de los índices de violencia urbana, producto de circunstancias complejas como el desempleo, el narcotráfico, segregación social, entre otras. Según Dammert (2013), utilizando datos de las Naciones Unidas de 2010, América Latina y el Caribe concentran la segunda mayor proporción de homicidios en el mundo. Aunque, como plantea la autora, en muchos países de la región, las tasas de homicidios en núcleos urbanos son más pequeñas que las tasas nacionales, las ciudades se han convertido en espacios de inseguridad. Así, BriceñoLeón (2007) se cuestiona: “¿Qué ha pasado para que la ciudad de América Latina, el lugar de los sueños y las esperanzas, se convirtiera en una amenaza para la mayoría de sus habitantes?" (p. 543).

Por otra parte, Amendola (2000) sostiene que las ciudades llamadas "posmodernas" a nivel mundial tienen como uno de sus 
organizadores más fundamentales el miedo, más que la propia violencia.

Y bien, ¿cómo se define el miedo? La Real Academia Española define la palabra "miedo" como una angustia, recelo o aprensión que alguien tiene por un riesgo o daño real o imaginario. Este instinto primario, característico de todos los animales, incluyendo el ser humano, se detona de manera natural ante la percepción de un peligro específico. Pero, ¿qué sucede cuando ese instinto deja de ser solo un reflejo y se convierte en una sensación común y continua en los habitantes de las ciudades, afectando completamente el modo de vida de esas personas? ¿Qué fenómenos son actualmente reconocidos como aquellos que generan un riesgo?

Autores como Virilio (2012) plantean que el miedo es parte de la realidad actual del mundo entero, porque la Tierra se está "encogiendo" y el espacio está desapareciendo al ser comprimido por el tiempo instantáneo, es decir, recibimos cada vez con más frecuencia, bombardeos mediáticos que nos permiten enterarnos de situaciones de peligro e inseguridad a nuestro alrededor y en todo el planeta; y que, por lo anterior, lo único que podemos hacer, en lugar de intentar lidiar con el miedo, es aceptarlo y buscar estrategias para administrarlo.

Para Bauman (2009), la aguda y crónica experiencia de inseguridad del mundo contemporáneo es un efecto de la convicción de que, más allá de los esfuerzos, es imposible obtener una seguridad completa, principalmente en un contexto en que las certezas y las formas de protección de la "modernidad sólida" se quedan diluidas, y la solidaridad social es destruida por el individualismo y la competencia. Cuando esto ocurre, los individuos experimentan una sensación de abandono. En este contexto, en el momento en que la gente percibe que no logrará una seguridad completa, busca explicar esta "falla" imaginando que fue causada por un acto de maldad premeditada, lo que implica la existencia de un delincuente. 
En esta línea, Reguillo (2008) afirma que la inseguridad y el miedo percibidos en las ciudades contemporáneas tienden a ser asociados a ciertos actores pensados (imaginados) como responsables del deterioro social y del caos urbano (alteridad amenazante), y a la construcción de murallas reales y simbólicas que permiten contener a esos actores.

Esa alteridad amenazante es comúnmente vinculada con la gente pobre, a la cual se le califica a partir de cuatro ejes principales: inutilidad, ignorancia, flojera y peligrosidad, existiendo una fuerte tendencia a pensarla como un lastre y un estorbo para la sociedad; al ser imaginados como "feos y sucios", las respuestas sociales enfatizan una solución violenta: hay que encerrarlos o exterminarlos ${ }^{3}$. De ahí que son evidentes las "estrategias de combate a la inseguridad" de los gobiernos; o las manifestaciones urbano-arquitectónicas que se producen en la ciudad, cuyos ejes vertebradores están en la invisibilización, el aniquilamiento y el combate frontal a dicho sector de la sociedad.

Así pues, el miedo en las ciudades es una mezcla de la violencia real con el imaginario y percepción social. De esta forma, no solo los elementos considerados objetivos, sino también aquellos más subjetivos, y los vínculos entre ellos, se conforman como dimensiones que influyen e impactan en la construcción de las ciudades latinoamericanas.

Manteniendo este panorama en consideración, este trabajo analiza el origen, los significados y las consecuencias del imaginario urbano del miedo en Latinoamérica, tomando las ciudades de Salvador de Bahía, en Brasil, y Monterrey, en México, como casos de estudio empíricos. A través de observación de la dinámica urbana, recolección de datos estadísticos sobre violencia, análisis

De acuerdo con Bauman (2009), en las ciudades europeas el miedo se corporifica en los extranjeros mientras en los EEUU el estigma recae sobre la llamada "underclass", grupos vulnerables considerados peligrosos, como los residentes de los guetos negros, parias urbanos, sin techo, mendigos, entre otros. Y en Latinoamérica, ¿quiénes son, más específicamente, los grupos de los cuales se desea proteger? 
de periódicos y entrevistas con habitantes de las urbes, el trabajo discute comparativamente las características del imaginario del miedo en las dos ciudades.

\section{Imaginarios urbanos y el miedo en Latinoamérica}

Desde una perspectiva sociológica, los estudios de imaginario remiten a los conceptos de "representación colectiva" y "representación social". Émile Durkheim (2002) fue el primero en trabajar directamente con esta comprensión. El término "representaciones colectivas" se refiere a categorías de pensamiento mediante las cuales una determinada sociedad elabora y expresa la realidad. Las representaciones tienen un origen social, pero ganan una vida independiente de la morfología (estructura) social, reproduciéndose y mezclándose con otras representaciones. De una manera general, para este autor, una representación colectiva es la forma como un grupo social se ve en relación con los objetos que lo afectan.

Desde el punto de la psicología social, Moscovici (2003) introduce al concepto más objetivista de Durkheim la comprensión de que los individuos tienen un rol en la construcción de las representaciones sociales, las cuales son creadas por ellos en el cuadro de los procesos de comunicación cotidiana. Así, conforme expresó Wagner (1998), las representaciones se configuran como un contenido mental estructurado sobre un fenómeno social relevante, que toma la forma de imágenes o metáforas compartidas con un grupo social.

Trabajando directamente con el concepto de imaginario, Hiernaux (2007) considera que los imaginarios en sí forman parte de la subjetividad individual y colectiva. De esta forma:

El imaginario funciona sobre la base de representaciones que son una forma de traducir en una imagen mental, una realidad material o bien una concepción. En otros términos, en la formación del imaginario se ubica nues- 
tra percepción transformada en representaciones a través de la imaginación, proceso por el cual la representación sufre una transformación simbólica. El imaginario es justamente la capacidad que tenemos de llevar esta transformación a buen término. (Hiernaux, 2007, p. 20)

Los imaginarios, por tanto, aportan un complemento a las representaciones, las transforman simbólicamente para ser no solo guías de análisis, sino también guías de acción. Ello proviene de su fuerza creativa y de su capacidad de generar imágenes mentales.

En esta perspectiva de las imágenes construidas, Hiernaux (2007) define que ellas tienen un lazo fundamental con el espacio. Más específicamente, el espacio urbano tendría la capacidad de activar la imaginación en función de la avalancha de estímulos visuales que promueve, haciendo surgir así los imaginarios urbanos. Esa característica ya había sido identificada por Simmel (1979) en sus análisis sobre los estímulos visuales, la vida mental y las formas de sociabilidad existentes en el espacio urbano.

Para Hiernaux (2007), los auténticos estudios de imaginarios urbanos buscan entender cómo se forman las representaciones (la ciudad imaginada) de los habitantes, o sea, comprender la visión de ciudad que impregna la mente de su gente. Más allá de ello, este abordaje implica comprender que los imaginarios expresan también la realidad material percibida, aunque reconstruida. Así, los estudios de imaginarios urbanos tienen que involucrarse también con las consideraciones de orden más bien objetivo, intentando construir vínculos entre las cuestiones objetivas y subjetivas. Lindón (2007) plantea también que involucrar los estudios urbanos en los imaginarios contribuye a "generar un capital teórico notorio" para abordar la ciudad desde su materialidad y desde lo socioeconómico.

También, desde esa perspectiva más urbana, Narváez (2013) afirma que los estudios sobre imaginarios urbanos suponen el enfrentamiento de lo que se interioriza del ámbito de vida de 
la persona y la ciudad, y plantea cuatro razones que explican la emergencia de la investigación sobre imaginarios urbanos en la ciudad contemporánea: la necesidad de enfoques más interpretativos acerca del significado de la vida urbana que no pueden explicarse con datos duros; el cambio de paradigma que está ocurriendo en las ciencias contemporáneas, ampliando los métodos positivistas y materialistas hacia métodos como los de complejidad; en relación al urbanismo, la evolución que esta ciencia está teniendo, en la que cada vez se comprende a la ciudad menos como un objeto y más como una idea, y las condiciones de la época actual, en la cual la supervaloración de la imagen, la privatización del espacio público y la conversión de la ciudad en una mercancía capitalista generada por los medios, influyen en la manera en la que percibimos y procesamos a nivel cognitivo el mundo.

Considerando este apartado más bien teórico, es relevante analizar el miedo en Latinoamérica a través de las dimensiones objetivas, pero también desde los imaginarios urbanos, si pretendemos ampliar la comprensión de esta región y las estrategias para abordar sus distintas problemáticas sociales y urbanas.

Las transformaciones ocurridas en la economía mundial en las últimas décadas -globalización, reestructuración productiva y neoliberalismo- impactaron fuertemente en la estructura de las ciudades mundiales, entre ellas las latinoamericanas. Como resultado de este proceso, muchos cambios espaciales -una metamorfosis urbana, como afirma De Mattos (2010)- estuvieron asociados a las transformaciones en los roles de planificación del Estado y en la fuerza del mercado inmobiliario en la gestión del desarrollo urbano. En términos sociales, en muchos países, como México y Brasil, los ajustes neoliberales contribuyeron a una crisis social marcada por desempleo, ampliación de la pobreza, de la vulnerabilidad social y de la violencia.

Según Briceño-León (2007), las ciudades de América Latina, que entre los años 1940 a 1970 representaron un lugar de espe- 
ranza, de seguridad y derechos, han visto aumentar sus tasas de violencia hasta casi llegar al doble desde los años 80. Esto ha llevado al crecimiento de los sentimientos de miedo e inseguridad, los cuales se distribuyen de manera más equitativa que la inseguridad real de la población, por cuenta de la acción de los medios de comunicación y los rumores sobre casos reales de violencia, lo que provoca subjetivamente que las sensaciones de temor se manifiesten de igual manera entre grupos victimizados y no victimizados.

De acuerdo con Amendola (2000), la violencia contribuye a explicar el crecimiento de las "ciudades blindadas", "burbujas" creadas por las personas no solo en sus hogares, sino en la vida cotidiana en general. Sin embargo, como dice el autor, más que la violencia, el organizador clave de la llamada ciudad "posmoderna" es el miedo a la violencia, generando así un elemento central en la constitución del nuevo panorama socioespacial basado en la arquitectura del miedo (Ellin, 2003), que mezcla la violencia real con el imaginario social.

Así mismo, Bauman (2009) examina cómo las ciudades contemporáneas se han convertido en espacios de miedo e inseguridad. Para este autor, las ciudades que surgieron paradójicamente para proporcionar seguridad a la población están actualmente asociadas con el peligro. Estas amenazas reales o percibidas para la integridad, generan estrategias de marketing que se construyen sobre la base de lo que él llamó "capital del miedo". Es decir, este imaginario está involucrado con múltiples condiciones materiales, desde la violencia real hasta una industria de seguridad, que moviliza sus estrategias a partir de la lógica de este capital del miedo.

Acerca de este proceso, Bauman (2009) advierte que si originalmente los muros y fosos de la ciudad construyeron un límite entre ciudadanos y extranjeros, en la actualidad toda la tecnología de la arquitectura del miedo produce un apartheid también entre los miembros de la misma sociedad. Este aislamiento es también la expresión de una mixofobia (miedo de mezclarse) o una 
negación de la heterogeneidad y de la diversidad que siempre han caracterizado a las ciudades y, por tanto, del espacio público y de la sociabilidad interclasista.

Así, para Caldeira (2000), el miedo no es solo de la violencia sino de la otredad. La protección no solo es del delito, sino contra las personas y los grupos sociales indeseables. Davis (2009) también señala que la arquitectura contemporánea y los espacios defendibles pretenden el control de multitudes mediante la construcción de barreras arquitectónicas y semióticas.

Según Bauman (2009), por cuenta de la vivencia en espacios de socialización cada vez más homogéneos, a raíz del miedo y de la segregación, lo más probable es que la gente se olvide del arte de la negociación de significados e incluso de un modus convivendi. Por lo tanto, para el autor, no es de extrañar que las personas experimenten una creciente sensación de horror ante la idea de encontrarse cara a cara con los extranjeros, que se vuelven más asustadores, ajenos, extraños e incomprensibles.

De acuerdo con Barbero (2003), el miedo, como modo de habitar y de comunicar, es una expresión de una angustia cultural colectiva, producto de factores como la pérdida del arraigo colectivo, o la manera como la ciudad normaliza la homogeneización impidiendo la expresión y las diferencias, erosionando las identidades colectivas mediante la exclusión y segregación urbanoarquitectónica.

La fobópole (ciudad del miedo), conforme el neologismo de Souza (2008), amplifica la segregación, destruye la solidaridad social, profundiza las estrategias de distinción y tiene un impacto directo sobre la cohesión social y la vida pública urbana. Todo lo anterior tiene manifestaciones profundas y contundentes en las ciudades latinoamericanas, en las que el proceso de fortificación, exclusión y capital del miedo, por medio de dispositivos y elementos arquitectónicos y urbanos, ha tenido una expresión bastante radical, según lo demuestran los análisis de Salvador de Bahía y Monterrey que se presentan a continuación. 


\section{Manifestaciones del imaginario del miedo en contextos urbanos: Salvador de Bahía, Brasil, y Monterrey, México}

La ciudad de Salvador de Bahía, ubicada en el nororiente de Brasil, actualmente es la tercera mayor ciudad del país, con una población de 2,9 millones de personas, polarizando una región metropolitana (RMS) de poco más de 3,5 millones de habitantes. A causa de las desigualdades regionales que se desplegaron en Brasil, de la industrialización tardía y limitada de Salvador y del fuerte impacto de los ajustes neoliberales en los años noventa, actualmente Salvador es una metrópoli periférica en el sistema económico y urbano brasileño (Carvalho y Pereira, 2008).

Esta condición periférica interfiere en las altas tasas de desigualdad y pobreza todavía existentes en la ciudad y, en función de estos elementos, en las tasas de criminalidad violenta. De hecho, los índices de violencia han aumentado considerablemente en Salvador. Este proceso comenzó en el paso de los años 80 a los años 90. Actualmente, Salvador vive con altos niveles de delitos dolosos violentos letales (homicidios, lesiones corporales, seguidas de muerte y robo) y también tiene tasas de homicidios por encima de la media nacional y del estado de Bahía. Por ejemplo, según el Octavo Anuario Brasileño de Seguridad Pública, mientras Brasil tenía en 2013 una tasa de homicidios intencionales de 25,2 por cada 100.000 habitantes y el Estado de Bahía una tasa de 36,1, Salvador tuvo una de 50 homicidios por cada $100 \mathrm{mil}$ habitantes, teniendo en cuenta los datos proporcionados por la Secretaría de Seguridad Pública (SSP-BA, 2015) y estimaciones de población del Instituto Brasileño de Geografía y Estadística (IBGE, 2015) ${ }^{4}$.

El Anuario Brasileño de Seguridad Pública no presenta datos sobre municipios y ciudades, solamente sobre estados de la federación y sobre todo el país. 
Según Cerqueira et al. (2014), citando datos del Comité de Naciones Unidas contra la Droga y el Delito, 67 de 88 países que ofrecen datos sobre tendencias de violencia mostraron un descenso en los homicidios en las últimas dos décadas. En general, los asesinatos están disminuyendo en la mayoría de las regiones, excepto América Latina y el Caribe, Sur y Centro de África y partes de Oriente Medio y Asia Central. En concreto, los autores enfatizan que solo 58 países tienen tasas más altas de 10 homicidios por cada 100.000 habitantes, valor considerado "aceptable". El Brasil encaja en este grupo, pero Salvador tiene una tasa cinco a seis veces mayor que dicho valor. La tabla I, a continuación, muestra los datos de algunos delitos cometidos en Salvador en los últimos cinco años:

Tabla I: Principales Delitos, Salvador, 2010-2014

\begin{tabular}{|l|l|l|l|l|l|l|l|l|}
\hline & $\begin{array}{l}\text { Homicidio } \\
\text { intencional }\end{array}$ & $\begin{array}{l}\text { Lesiones } \\
\text { corporales } \\
\text { seguidas de } \\
\text { muerte* }\end{array}$ & $\begin{array}{l}\text { Robo } \\
\text { seguido de } \\
\text { muerte }\end{array}$ & $\begin{array}{l}\text { Intento de } \\
\text { homicidio }\end{array}$ & Estupro & $\begin{array}{l}\text { Robo a } \\
\text { buses }\end{array}$ & $\begin{array}{l}\text { Hurto de } \\
\text { vehículos }\end{array}$ & $\begin{array}{l}\text { Robo de } \\
\text { vehículos }\end{array}$ \\
\hline $\mathbf{2 0 1 0}$ & 1639 & & 23 & 776 & 520 & 973 & 1313 & 3857 \\
\hline $\mathbf{2 0 1 1}$ & 1528 & & 18 & 996 & 442 & 1433 & 1391 & 4847 \\
\hline $\mathbf{2 0 1 2}$ & 1576 & 52 & 32 & 1111 & 623 & 1627 & 1481 & 6738 \\
\hline $\mathbf{2 0 1 3}$ & 1429 & 29 & 27 & 869 & 651 & 1210 & 1417 & 6125 \\
\hline $\mathbf{2 0 1 4}$ & 1321 & 26 & 50 & 691 & 521 & 1492 & 1749 & 6371 \\
\hline * Los datos de 2010 y 2011 no estaban disponibles. \\
\hline
\end{tabular}

Fuente: Secretaría de Seguridad Pública de Bahía (SSP-BA, 2015).

Como se puede observar, la ciudad de Salvador ha experimentado tasas alarmantes de violencia, asesinatos, robos en transportes públicos colectivos, hurtos y robo de vehículos. La gente vive en la práctica una experiencia cotidiana del miedo, del cuidado, de mirar a un lado y al otro, la desconfianza de los demás y, sobre todo, la evitación de ciertos barrios y espacios, en ciertos días o en momentos específicos. Sin embargo, conforme lo discutido anteriormente, más que la violencia, Salvador ha sido impactada fuertemente por el imaginario del miedo, cada vez más estimulado por los medios de comunicación, los cuales 
han reflejado la inseguridad en Salvador y desempeñan un papel clave en la expansión de la sensación de miedo que reina en la ciudad, la cual continúa a pesar de la caída de los índices de homicidios en los últimos años (en 2010 la tasa de homicidios intencionales por cada 100 mil habitantes fue de 61, y en 2014 el número disminuyó a 46, aunque continúa siendo cuatro veces más grande que el aceptable). Con el sugerente título "Ciudad del miedo", el informe del 15 de enero de 2010 de un periódico llamado Jornal da Metrópole muestra la "escalada de la violencia en Salvador", especialmente aquella que "acosa" a la clase media en los barrios de más alto ingreso, haciendo hincapié en el "pánico" que esto ha generado en la periferia (heredera histórica de la violencia urbana) y, más recientemente, también en los barrios de la clase media. El informe comienza así:

Cámaras, cercas eléctricas, rejas y barrios cerrados. Todo parece ofrecer seguridad y "escudo" para quien puede pagar para evitar que la violencia que reina en las calles no llegue a su puerta. Pero la ilusión se acaba cuando es necesario salir de casa y enfrentarse a la realidad de Salvador. (Pérez, 2010, p. 4).

Paralelamente al aumento de la violencia, también se extiende su visibilidad y el imaginario alrededor de esta realidad. Se multiplican en Salvador reportajes y programas sobre violencia y la acción de la policía, que ponen en relieve los casos de asesinatos, robos, secuestros, explosiones de cajeros automáticos, robos en bares y restaurantes, entre otros.

En un reportaje del mismo periódico, del 27 de noviembre de 2014, respecto del asesinato de un trabajador informal que se encarga del estacionamiento de automóviles en las calles (llamados flanelinhas en portugués, por cuenta de las franelas que generalmente llevan consigo), se hace la pregunta: “¿Era necesario llegar a este nivel?", como se aprecia en la figura 1. Asimismo, en la figura 2 se puede observar la portada de un importante periódico de la ciudad, que habla sobre el asesinato de un jardinero. 


\section{Meatrópole}

ASSASSINATODEFLANELINHA:

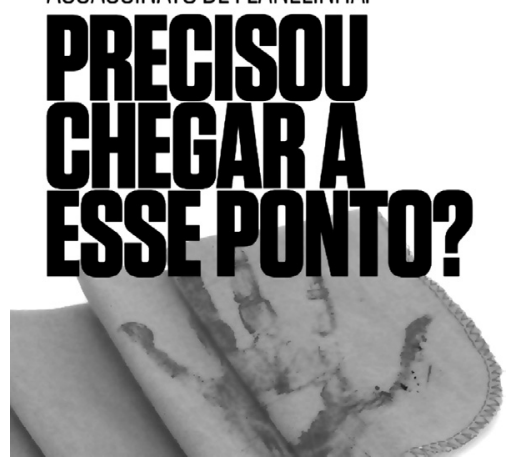

Figura 1: Manifestación del imaginario del miedo en un periódico de Salvador de Bahía. Fuente: Silveira, S., 2014.

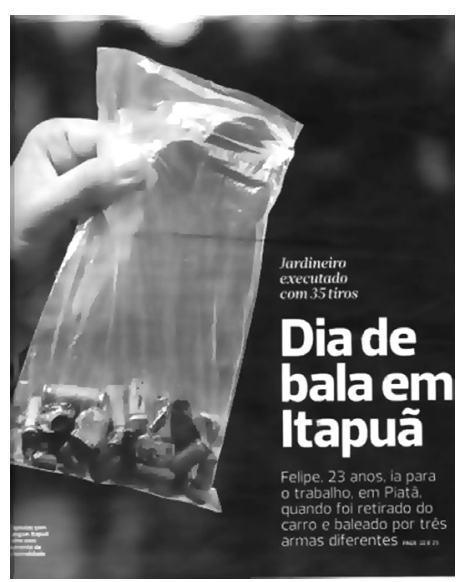

Figura 2: La portada dice: "día de bala en Itapuã (un barrio de Salvador). Fuente: Santos, G., 2015.

Frente a un contexto en el que cada vez la gente tiene más miedo, la "solución" más inmediata para las personas con mayores recursos ha sido la búsqueda de alternativas individuales, como el aumento de la demanda de enclaves fortificados, desarrollos percibidos como seguros, protegidos y lejanos a la violencia. Actualmente en Salvador hay oferta de "microciudades", desarrollos que ofrecen todas las actividades urbanas, vivienda, consumo, trabajo y esparcimiento en un espacio cerrado. Y el ápice de este proceso es la oferta actualmente existente de viviendas sociales bajo las características de condominios cerrados (Arantes, 2011).

En un trabajo sobre los condominios cerrados de niveles medios y altos en la RMS (Arantes, 2011), se tuvo la oportunidad de estudiar los imaginarios urbanos de los residentes sobre los condominios donde vivían y sobre los espacios de la ciudad. El miedo a la violencia, pero también el miedo de mezclarse, fueron uno de los principales hallazgos.

En el imaginario de los residentes, la vida en los condominios es vista como mejor y más tranquila que en la ciudad. Ello porque, para los residentes, el control de quién entra y sale permite a las personas vivir "como antes", es decir, pueden dejar sus coches, 
puertas y ventanas abiertas, puede sentarse en frente de sus casas con confianza, caminar a pie en las calles por la noche y dejar a sus hijos entretenerse sin preocuparse.

Para ellos, el regreso a casa es un alivio, es siempre un placer. Este imaginario se contrapone a uno negativo sobre la ciudad. El miedo tiene un rol relevante en este proceso.

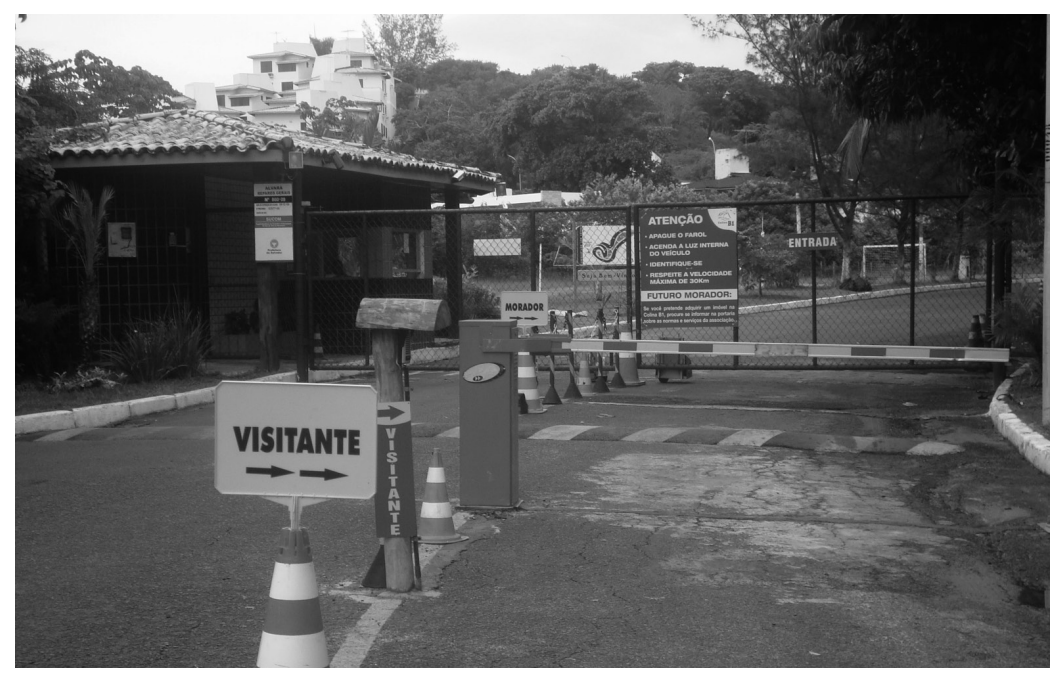

Figura 3: Variedades de equipamientos de seguridad: casetas de vigilancia, rejas y videocámaras - Entrada de un condominio cerrado en Salvador de Bahía. Fuente: Arantes, 2011.

Muchos de los entrevistados dijeron sentirse inseguros al salir de su condominio. Como razones de la inseguridad, los encuestados destacan los altos niveles de violencia en Salvador y dicen que, cuando están en la calle, se está sujeto a todo tipo de violencia. Para muchos el condominio es un "oasis" de seguridad $\mathrm{y}$ tranquilidad en medio de la ciudad.

Para analizar los imaginarios de los residentes sobre la ciudad, se preguntó en las entrevistas su impresión acerca de algunos espacios y de algunas fiestas populares realizadas en las calles, hitos simbólicos urbanos y culturales de Salvador. También se les preguntó su opinión sobre los barrios populares cercanos a sus condominios. 
Sobre los espacios de la ciudad, en general los imaginarios se asociaban con tres elementos: a) el déficit de la estructura urbana y la falta de administración del Estado; b) la heterogeneidad social, excesiva mezcla de personas, y c) la falta de seguridad, la cual surge no solo de las dificultades del Estado, sino también de la violencia producida por las "clases peligrosas".

El miedo ejerce ahí un rol fundamental. En los imaginarios de los encuestados, los espacios públicos son vistos como "antros de marginales" (sic), como señaló uno de los entrevistados. Estos espacios concentrarían muchas transas de drogas, "drogadictos" (sic), ladrones, asaltantes y "pueden ocurrir tiros, pueden apuñalarme; me pueden robar mi bolso", como destaca otra entrevistada. De acuerdo con estos imaginarios, la policía no puede contener la delincuencia y estos sitios están más sometidos a este tipo de violencia.

Sobre las poblaciones, los imaginarios se basaban principalmente en prejuicios de clase y la estigmatización de las zonas populares. En general, el estigma se basaba en la idea de que las áreas de urbanización popular son peligrosas debido al narcotráfico. Este estigma genera dos tipos de comportamientos. Por un lado, reafirma el miedo y la segregación, y, por otro, construye una "sorpresa", conforme fue mencionado por una entrevistada, al descubrir que en estos barrios también hay "gente buena, honesta, trabajadora" (sic) "personas normales de familia" (sic).

Esto se mostró muy fuerte principalmente entre los jóvenes encuestados, que tenían un imaginario lleno de miedo de las poblaciones. Sus argumentos, en la mayoría de los casos, ni siquiera se basaban en experiencias, sino en estereotipos y estigmas; se resumían en declaraciones como "malo, es peligroso", "nunca entré, es un mal lugar" o "nunca lo haría, porque creo que es peligroso", expresando la falta de conocimiento (e interés).

Sin embargo, el "miedo" no es solo de la violencia, sino también de los grupos indeseables y de la mezcla social. La composición social heterogénea también molesta a algunos de los entrevistados, quienes incluso dijeron que la mezcla de diversos 
segmentos sociales hace que haya una proporción muy grande de "gente fea" (sic) en los espacios de la ciudad. Como dijo un entrevistado de una fiesta popular, que antiguamente reunía muchos grupos sociales distintos, "hoy no me gusta por el acceso, la seguridad y la estética. Hay muchas personas feas [...]".

Este prejuicio "estético" denota clasismo y racismo, ya que hablar en Salvador de las clases populares, a las que los entrevistados llamaban "feas", significa fundamentalmente hablar en su mayoría de gente de raza negra. Las clases medias y altas se molestan con el estilo de otros niveles sociales, criticando su estética, su forma de ser y sus gustos "dudosos" por ciertos tipos de música y danza. Mientras se desarrolla esta devaluación de los espacios abiertos de la ciudad, se crea al mismo tiempo una valorización muy grande de los espacios privados, en donde pueden sentirse más seguros, pues la ciudad, en los imaginarios de la gente, está cada vez más peligrosa. Como dijo una joven encuestada sobre un Mall:

En el centro comercial se tiene la idea de que usted está allí protegido, con guardias de seguridad del centro comercial, entonces, siempre pensamos en nuestra seguridad... Usted sabe que podrá sacar su iPhone de su bolsillo sin problemas... [En el centro comercial] hay la idea de que estás a salvo alli, adentro de aquel espacio allí. Allí usted será capaz de encontrar sus amigos, tranquilo, con seguridad.

Conforme se observa, actualmente la vida urbana en Salvador de Bahía está atrapada con la cuestión de los imaginarios urbanos del miedo: el miedo de la violencia, el miedo de los espacios abiertos, de las personas diferentes, o sea, el miedo de la ciudad.

Por otra parte, al analizar el caso de la ciudad de Monterrey, capital del estado de Nuevo León, México, podemos encontrar diversas similitudes con Salvador de Bahía: Monterrey se localiza en el nororiente de México, a dos horas de la frontera con Estados Unidos. Y también, al igual que Salvador de Bahía, es la tercera ciudad en importancia y población del país, con alrededor de 4,5 millones de habitantes en su área metropolitana (AMM). La otro- 
ra "capital industrial de México" actualmente ha diversificado su economía hacia la tecnología y los servicios, como la mayoría de las ciudades postindustriales, debido a las reestructuraciones económicas globales y locales, lo cual ha generado, al igual que en cualquier otra metrópoli, incrementos en problemáticas urbanas, sociales y medioambientales, como migración, desempleo, pobreza, vulnerabilidad social, fragmentación territorial, urbanización sin dotación de equipamiento y, por consecuencia, inseguridad, violencia, y particularmente un incremento en la delincuencia organizada (Fitch y Chávez, 2011), más notoriamente a partir de 2009-2010, en que el gobierno federal decidió declarar la guerra a los cárteles del narcotráfico, suscitando así una ola de enfrentamientos, homicidios y terror en general, no solamente en Monterrey, sino en casi todas las ciudades de la región fronteriza con Estados Unidos.

De acuerdo con datos del Instituto Nacional de Estadística y Geografía de México (INEGI, 2015), el año 2011 ha sido el más violento de la década, con un registro de 24 homicidios por cada cien mil habitantes en todo el país (como se mencionó, el valor aceptable en el nivel mundial es de 10), y 45 homicidios por cada cien mil habitantes en el Estado de Nuevo León.

Tabla II: Principales Delitos, Monterrey, 2010-2014

\begin{tabular}{|c|c|c|c|c|c|}
\hline & $\begin{array}{c}\text { Homicidio } \\
\text { intencional }\end{array}$ & Secuestro & $\begin{array}{c}\text { Robo con } \\
\text { violencia }\end{array}$ & $\begin{array}{c}\text { Robo de } \\
\text { vehículos }\end{array}$ & $\begin{array}{c}\text { Robo a } \\
\text { buses** }\end{array}$ \\
\hline $\mathbf{2 0 1 0}$ & 828 & 18 & 11546 & 15493 & \\
\hline $\mathbf{2 0 1 1}$ & 2003 & 51 & 20596 & 21043 & \\
\hline $\mathbf{2 0 1 2}$ & 1459 & 61 & 11225 & 11146 & \\
\hline $\mathbf{2 0 1 3}$ & 719 & 46 & 6652 & 3952 & \\
\hline $\mathbf{2 0 1 4}$ & 262 & 25 & 2665 & 1350 & \\
\hline
\end{tabular}

* Los datos encontrados son solo hasta junio de 2014.

** En Nuevo León, la Procuraduría de Justicia estatal no cuenta con estadísticas de robo a transporte público; sin embargo, cifras nacionales colocan a la entidad como una de las primeras tres en donde se comete este delito (Vargas, 2013).

Fuente: Observatorio Nacional Ciudadano (2016). 
Y es precisamente por el aumento en la delincuencia organizada y la inseguridad -cuyo discurso tiene, al igual que en Salvador, dos dimensiones: la objetiva, basada en sucesos reales, y la subjetiva, basada en los imaginarios, potencializados por los medios de comunicación-, que la ciudad de Monterrey se ha vuelto una comunidad del miedo, donde los desarrolladores inmobiliarios han fomentado también, durante las últimas décadas, el modelo de desarrollos habitacionales cerrados, vendiendo como un "plus" la dotación de seguridad habitacional, a partir de la construcción de muros y rejas que interrumpen la circulación pública y el control restringido de acceso por medio de casetas de vigilancia, videocámaras, mallas electrificadas, entre otros elementos arquitectónicos.

Aunque a partir de 2011 los índices de violencia y homicidios han descendido considerablemente (según los mismos datos del INEGI, en 2014 el Estado de Nuevo León registró un valor de 11 homicidios por cada cien mil habitantes), la percepción de inseguridad y el imaginario del miedo continúan latentes en la población del Área Metropolitana de Monterrey, pues, como se mencionó, además del imaginario del miedo, impuesto y desarrollado como estrategia de mercado por parte de inmobiliarias y desarrolladores urbanos, los medios de comunicación también contribuyen a fomentar la percepción de inseguridad en los habitantes de la ciudad. Del mismo modo que, en el caso de estudio de Salvador de Bahía, el periódico Jornal da Metrópole con sus reportajes incrementa la sensación de pánico en los ciudadanos respecto de la violencia urbana, en Monterrey sucede el mismo fenómeno.

Como ejemplo se puede observar un mapa interactivo que el periódico El Norte, el diario más importante de la región, realizó en su página web, llamándolo "Mapa del Crimen 2011", cuyo objetivo era señalar las zonas de riesgo en la ciudad mediante una serie de puntos rojos, los cuales, cuando el lector los señalaba, de manera más específica podía leer datos como los siguientes: "Tiran cuerpo torturado", "Alarma tiroteo en sector 
Valle Oriente", "Lesionan a inocente en tiroteo", entre otros, sin mencionar el encabezado amarillista que se presenta en la parte superior del mapa, cuya leyenda dice: "La ola de violencia sin precedentes en Nuevo León tiñe diariamente de rojo el mapa metropolitano con ejecuciones, homicidios y constantes ataques y enfrentamientos entre bandas rivales del crimen organizado y de éstas con las autoridades. Ubica aquí los lugares donde ocurrieron esos hechos y los detalles de la guerra desatada por el crimen" (ver figura 4).

\section{ELNORTE.COM MAPA DEL GRIMEN 2011}

\section{UBICA ZONAS DE RIESGO}

La ola de violencia sin precedentes en Nuevo León tiñe diariamente de rojo el mapa metropolitano con ejecuciones, homicidios y constantes ataques y enfrentamientos entre bandas rivales del crimen organizado y de éstas con las autoridades. Ubica aquí los lugares donde ocurrieron esos hechos y los detalles de la guerra desatada por el crimen.

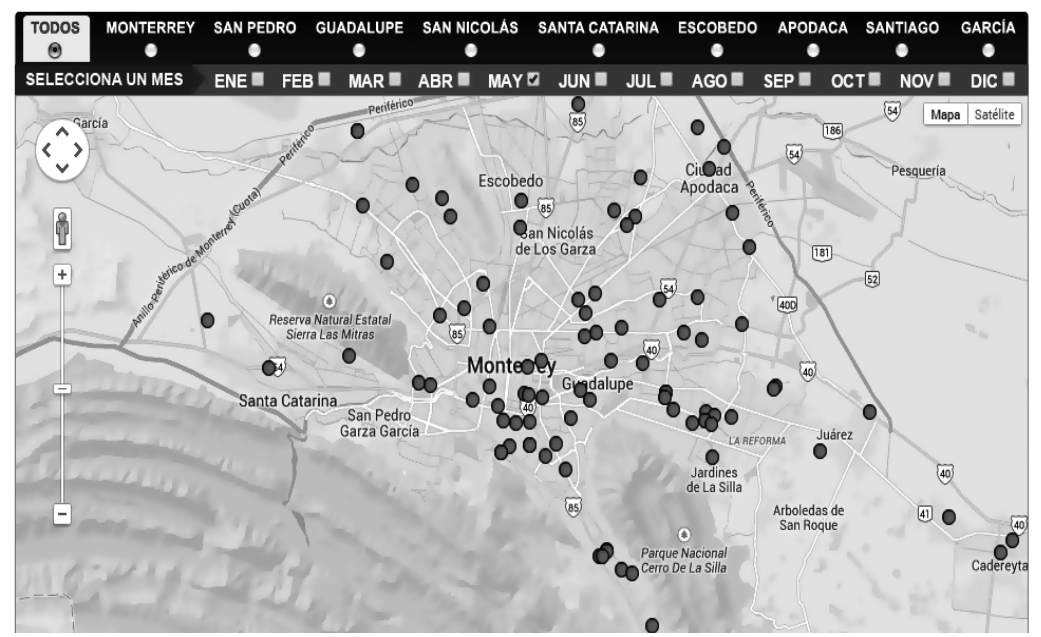

Figura 4: Mapa del crimen 2011 del periódico El Norte en Monterrey, México. Fuente: El Norte, 2015.

Y como un ejemplo más reciente se muestra la figura 5, en la que se puede observar un encabezado del diario Zócalo en diciembre de 2014, cuya redacción contribuye a incrementar la sensación de alarma y miedo en la sociedad: 


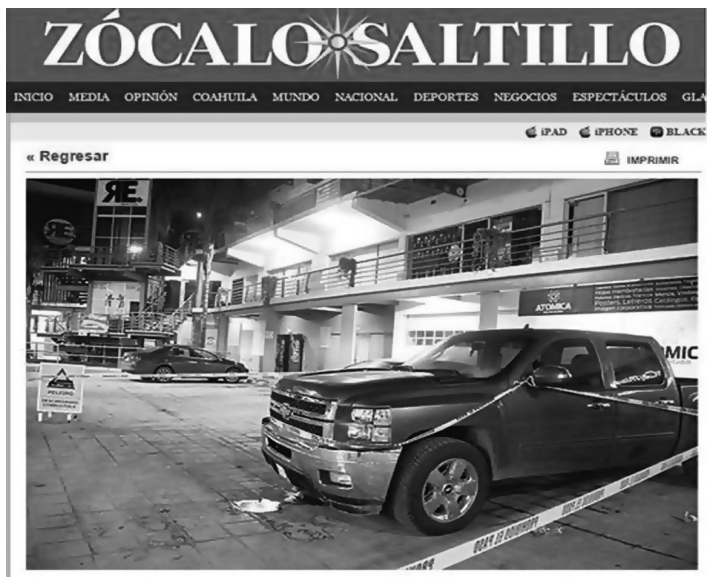

Centro de Monterrey, ipeligro!: zona de miedo

[Nuevo León]

Por Agendias $24122014-0503$ AM

Monterrey, NL.- La inseguridad que se vivió en el Centro de Monterrey, en especial en centros nocturnos, se reaviva con el ataque al bar RE, en San

Nicolás de los Garza, lo cual mantiene en "suspenso" y con miedo a inversionistas, esos que han dejado morir al primer cuadro de la capital y que amenaza con extenderse al resto del área metropolitana.

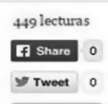

Figura 5: Encabezado del diario digital Zócalo Saltillo. Fuente: Zócalo, 2014.

También, es importante mencionar un estudio comparativo sobre la calidad de los noticieros de tres televisoras locales de Monterrey, realizado por Hernández, L., et al. (2008), en el cual se evidencia el peso y el tiempo que la "nota roja" tiene en la programación diaria. Entre algunos de los hallazgos del mencionado estudio se puede indicar, por ejemplo, que las tres televisoras dedican un 35\% de su programación a noticieros, en los cuales se da un porcentaje mayor de notas violentas en relación con las no violentas (aproximadamente un 34\%). Asimismo, se observó que las tomas a heridos, personas llorando, balas en el suelo, grupos de curiosos y manchas de sangre son las que predominan en las emisiones; que las palabras "trágico" o "tragedia" son recurrentes, incluso cuando no se produjeron fallecimientos ni heridos graves; o que hay una marcada tendencia a mostrar primero los aspectos más espectaculares de una situación, tales como fierros retorcidos, ambulancias con la sirena encendida, heridos inmovilizados en camilla, para luego precisar que "por fortuna" o "afortunadamente" no ocurrió un daño mayor. 
Por otro lado, al igual que en el caso de estudio de Salvador de Bahía, en Monterrey también se entrevistó a algunos residentes de condominios privados, ya que son la manifestación arquitectónica más evidente del imaginario del miedo en la ciudad, con la finalidad de conocer un poco más acerca de la percepción colectiva al respecto. Las entrevistas se realizaron respecto a los condominios en los que viven, así como a la percepción sobre los barrios populares o informales cerca de ellos, y de la ciudad en general. Los hallazgos resultan ser, a grosso modo, muy parecidos a los encontrados en los habitantes de la ciudad brasileña: en Monterrey, los habitantes de los condominios analizados también perciben dichos lugares como una especie de "oasis" de protección y tranquilidad, en los que las amas de casa o los hijos de las familias pueden desarrollar sus actividades de manera segura: "Para mí, lo más importante es la seguridad de mis hijos, de mi familia...", aseguró una de las entrevistadas, "...en este lugar puedo tener la tranquilidad de que mis hijos pueden jugar en el parque sin que les pase nada".

En cuanto a la población, a diferencia de la percepción en Salvador de Bahía, en la que la gente de raza negra es señalada como sospechosa, violenta, fea, etc., aunque en esta ciudad la cuestión racial esté profundamente involucrada con la cuestión de clase, en Monterrey no se percibieron prejuicios de discriminación racial como tal, pero sí prejuicios clasistas, de "estatus", en relación a que el vivir dentro de un condominio privado posiciona al habitante en un nivel social más alto y poderoso que los que no viven en esos lugares, y una estigmatización y rechazo/indiferencia hacia los habitantes de barrios populares o informales: “...pues lo único que no me gusta de vivir aquí, son las colonias feítas que están aquí enseguida... si no estuvieran, la zona tendría más plusvalía... pero pues uno no se mete a esas colonias...", comentó otra de las entrevistadas. "...yo me acuerdo que cuando la cosa se puso muy fea hace algunos años, ni siquiera nos metíamos a la calle de Río Nazas, porque decían que te secuestraban o que te podía tocar una balacera... preferíamos rodear por otras calles aunque nos tardáramos más...". 
Así pues, también se puede afirmar que el imaginario urbano del miedo en Monterrey es latente: miedo a secuestros, miedo a los tiroteos entre el crimen organizado y las autoridades, miedo a los espacios públicos heterogéneos, miedo a transitar por ciertas vialidades o zonas de la ciudad, etc. Miedos, algunos basados en fundamentos reales, pero muchos otros basados solamente en la percepción de gente que nunca ha sido víctima de ningún tipo de violencia. Y sin lugar a dudas, un "capital del miedo" impulsado por el mercado inmobiliario y los medios de comunicación.
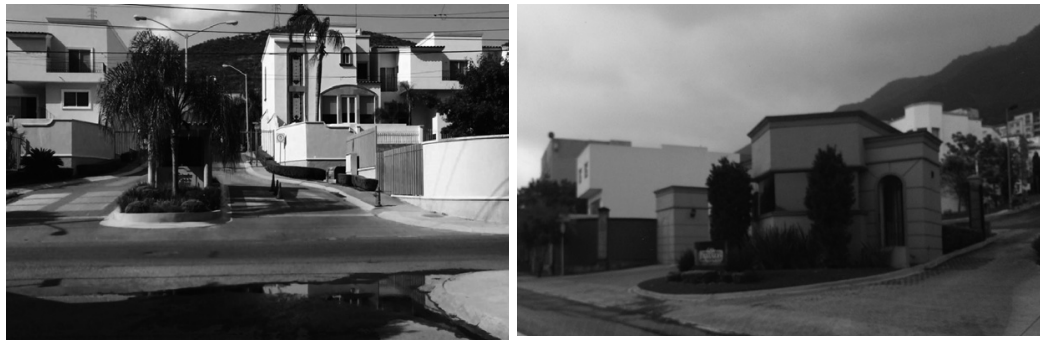

Figuras 6 y 7: Manifestaciones arquitectónicas del imaginario del miedo en la entrada de dos condominios privados en Monterrey: casetas de control de acceso, bardas perimetrales, rejas eléctricas, entre otros. Fotografías de Javier Gómez (autor). Monterrey, 2015.

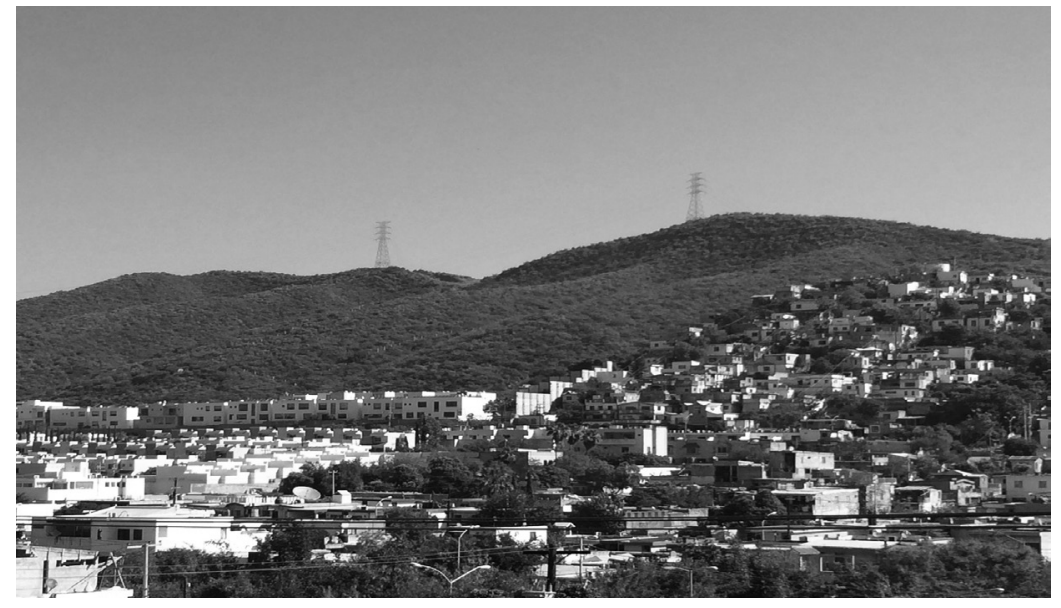

Figura 8: Construcción de condominio privado (izquierda) junto a un asentamiento informal (derecha) en Monterrey, divididos por un muro de gran altura. Fotografía de Javier Gómez (autor). Monterrey, 2015. 


\section{Consideraciones finales}

El objetivo de esta reflexión era comprender el fenómeno del imaginario del miedo en las ciudades latinoamericanas, estudiadas a partir del análisis empírico comparativo de las ciudades de Salvador de Bahía y Monterrey, con la finalidad de comprender más acerca de sus orígenes, significados y consecuencias. En términos metodológicos, interesaba identificar las similitudes y diferencias de estas experiencias urbanas, como una forma de comprender mejor el fenómeno estudiado en Latinoamérica. Como hilo conductor de los análisis, el concepto de "imaginario urbano" fue muy útil, toda vez que permitió comprender tales procesos desde la perspectiva de las personas, haciendo una mezcla entre elementos objetivos y subjetivos.

Entre los principales resultados, se puede destacar que, como se observó a lo largo de este artículo, el imaginario del miedo es una de las características más relevantes de los contextos urbanos analizados, hecho que se expresa en múltiples manifestaciones de segregación, exclusión social y urbanística, más allá de las estrategias de distinción y evitación de los encuentros con los grupos considerados indeseables y peligrosos, como los pobres y los negros, siendo más relevante en Salvador que en Monterrey, donde la configuración étnica es distinta.

Asimismo, se puede afirmar que el origen de estos imaginarios del miedo es resultado de factores complejos, desde elementos más objetivos, profundos y estructurales, como la fuerza del mercado inmobiliario y del capital del miedo -aumentado por los medios de comunicación-, y la ampliación de los índices de violencia real, como de otros más bien subjetivos, como la evitación del otro y la mixofobia.

De una manera general, se puede decir también que, más allá de las características particulares de las múltiples ciudades latinoamericanas, los procesos de miedo, evitación al otro, prejuicios, privatización y segregación, parecen ser fenómenos comunes que se repiten en distintas escalas. Tales fenómenos no ocurren 
solamente en Salvador o Monterrey, sino en muchas otras ciudades. El caso de Santiago de Chile, por ejemplo, es paradigmático en este sentido. Según Dammert (2013), mientras esta ciudad es una de las más seguras de Latinoamérica, sus ciudadanos viven una vida temerosa, desarrollando estrategias de convivencia (o evitación) urbana y restricción del tránsito por la ciudad, lo que demuestra la autonomía del miedo en respuesta a la incidencia criminal. En este sentido, el miedo adquiere una conformación más bien simbólica, agregando formas de prejuicios y estigmas, de un modo en que el miedo no es solo de la violencia, sino de la otredad, de los sujetos urbanos diferentes.

Así, el imaginario del miedo adquiere como significado central una justificación para las formas clasistas y racistas de segregación, tanto residencial como del uso de los espacios. La consecuencia principal para las ciudades latinoamericanas es que ellas pierden su potencial socializador, civilizador, dejando de ser un espacio de tolerancia, encuentros y de producción de urbanidad, convirtiéndose en un lugar del miedo, del prejuicio, de la evitación y de la distinción.

El temor al delito produce fragmentación de un modo en que los espacios de anonimato y temor se vuelven más frecuentes e importantes que aquellos de intercambio y diferencia (Dammert, 2013). Frente a esta realidad, ¿qué se puede hacer? O, ¿qué caminos podrían seguir las políticas públicas de intervención interesadas?

Considerando el contexto más amplio de estos procesos, conforme planteó De Mattos (2014), si se acepta que las características actuales de las ciudades contemporáneas están involucradas con la nueva fase de modernización capitalista, que ha profundizado las tendencias de privatización y mercantilización del desarrollo urbano, las propuestas de estrategias de intervención urbana en las ciudades deben necesariamente proponerse a la previa transformación del orden social general que las creó. Mientras las fuerzas mencionadas continúen de la forma en la que están 
hoy en día, es poco probable que suceda un cambio radical en los imaginarios del miedo.

No obstante, como planteó en otra oportunidad Gramsci (2000), es necesario unir al pesimismo de la razón, el optimismo de la voluntad, de forma que algunas iniciativas pueden contribuir para contrarrestar tales tendencias, actuando como acumulación de fuerzas hacia cambios contrahegemónicos. Algunas investigaciones, por ejemplo, lograron demostrar cómo la convivencia con la otredad suele contribuir para la disminución de los prejuicios y miedos (Sabatini, et al., 2013).

Por lo anterior, para colaborar a dicha disminución y cambio en el imaginario del miedo y para avanzar hacia una sustentabilidad real en las ciudades latinoamericanas, es posible empezar con el desarrollo de estrategias de acción puntuales. No se puede hablar de sustentabilidad en las ciudades, ni de indicadores de calidad de vida, disminución de la pobreza, mejora al medioambiente, etc., si al mismo tiempo la realidad es que vivimos en ciudades dominadas por el miedo, la individualización, la privatización y la paranoia del otro, de lo heterogéneo y de lo público, lo cual provoca prácticas urbano-arquitectónicas que son todo lo contrario a lo que el concepto de sustentabilidad urbana promueve "en teoría".

Así pues, independientemente de las estrategias del gobierno para combatir la delincuencia y la inseguridad, se deben realizar estrategias para combatir la homogeneización y la discriminación y segregación espacial, para hacer que el ciudadano vuelva a confiar en el otro, para cambiar la percepción acerca de la otredad, es decir, desarrollar estrategias de alteridad que promuevan la integración comunitaria colectiva, y esas estrategias pueden ser de cualquier tipo: campañas publicitarias, organización de fiestas y eventos comunitarios, creación y rehabilitación de espacios públicos y, sobre todo, concientización de la población acerca de las consecuencias negativas que la arquitectura y urbanización del "miedo" ocasionan socialmente y urbanísticamente hablan- 
do. Por ello, es importante la realización y difusión de estudios como el presentado. Es fundamental reconocer la fuerza que los imaginarios tienen en la sociedad, y que si se logra cambiar esas "representaciones colectivas", como las llama Durkheim, y dirigirlas hacia acciones más positivas, objetivos más grandes y concretos pueden ser alcanzados.

\section{Referencias}

Amendola, G. (2000). La ciudad postmoderna: magia y miedo de la metrópolis contemporánea. Madrid: Celeste Ediciones.

Arantes, R. (2011). Fugindo dos "males" da cidade: os condomínios fechados na grande Salvador. (Tesis de magíster). Programa de posgrado en Ciencias Sociales de la Universidad Federal de Bahía, Brasil.

Barbero, J. (2003). Los laberintos urbanos del miedo. Universitas Humanística, 56, 69-79.

Bauman, Z. (2009). Confiança e Medo na Cidade. Rio de Janeiro: Jorge Zahar Ed.

Briceño, R. (2007). Violencia urbana en América Latina: un modelo sociológico de explicación. Espacio Abierto, 16 (003), 541-574.

Caldeira, T. (2000). Cidade de Muros. São Paulo: Edusp.

Carvalho, I. y Pereira, G. (orgs.). (2008). Como Anda Salvador. Salvador: EDUFBA.

Cerqueira, D., Muggah, R., Peres, M. \& De Lima, R. (2014). Defendendo mais paz, segurança e justiça na Agenda Pós-2015 da ONU. En Anuário Brasileiro de Segurança Pública, 124-133 São Paulo: Fórum Brasileiro de Segurança.

Davis, M. (2009). Cidade de Quartzo. São Paulo: Boitempo.

Dammert, L. (2013). Santiago de Chile: segregación y cotidianidad del temor. En J. Noyola, C. De Mattos, y A. Orellana. Urbanización en tiempos de crisis: impactos, desafíos y propuestas. Santiago de Chile: Instituto de Estudios Urbanos y Territoriales.

De Mattos, C. (2010). Globalización y metamorfosis metropolitana en América Latina. Quito: Olacchi.

De Mattos, C. (2014). Gobernanza neoliberal, financiarización y metamorfosis urbana en el siglo XXI. En: XIII Seminário Internacional da RII 
- Rede Iberamericana de Pesquisadores sobre Globalização e Território. Conferencia de apertura. Salvador, 2014.

Durkheim, É. (2002). As formas elementares da vida religiosa. São Paulo: Martins Fontes.

El Norte, (2015). Mapa del crimen en Monterrey. Recuperado en enero de 2015 de: http:/ /gruporeforma.elnorte.com/libre/ offlines/mty/mapas/MapaDelCrimen2011.htm

Ellin, N. (2003). Fear in city building. The Hedghog Review, 5(3), 43-61.

Fitch, J. y Chávez, H. (2011). Dinámica territorial segregativa en Monterrey, México: El caso de ciudad Solidaridad [Versión Electrónica]. ACE: Architecture, City and Environment = Arquitectura, Ciudad y Entorno, 16 (6), 91-110.

Gramsci, A. (2000). Cadernos do cárcere: Maquiavel. Notas sobre o Estado e a política. V. 3. Rio de Janeiro: Civilização Brasileira.

Hernández, L., Márquez, L. y Ponce, J. (2008). Estudio de la calidad de los noticieros de la televisión local en Nuevo León, México: el caso de Multimedios Televisión, Televisión Azteca noreste y Televisa Monterrey. Revista Questión, 1(20). Recuperado de http://perio.unlp.edu.ar/ojs/index.php/question/ article/view / 690

Hiernaux, D. (2007). Los imaginarios urbanos: de la teoría y los aterrizajes en los estudios urbanos. Revista Eure, XXXIII (99), 17-30.

IGBE (2015). Instituto Brasileño de Geografía y Estadística. Recuperado en octubre de 2015 de http:/ / www.ibge.gov.br

INEGI (2015). Boletín especial homicidios en México año 2014. Instituto Nacional de Estadística y Geografía. Recuperado en septiembre de 2015 de: http://www.inegi.org.mx/saladeprensa/boletines/2015/especiales/especiales2015_07_4.pdf

Lindón, A. (2007). La ciudad y la vida urbana a través de los imaginarios urbanos. Revista Eure, XXXIII, 7-16.

Pérez, F. (15 de enero de 2010). Pânico em Salvador: escalada da violência em Salvador atinge tanto a periferia quanto os bairros de classe média da cidade. Jornal da Metrópole, 4,8.

Silveira, S. (27 de noviembre de 2014). O medo está dos dois lados. Jornal da Metrópole, 4,6.

Moscovici, S. (2003). Representações sociais: investigações em psicologia social. Petrópolis: Vozes. 
Narváez, A. (2013). Por qué estudiar a la ciudad desde los imaginarios urbanos. En D. González, A. Narváez, H. Roldán, y J. Chávez (compiladores). Ciudades Red: Una visión a través de los imaginarios urbanos, 77- 94. México: Universidad de Guadalajara.

Reguillo, R. (2008). Sociabilidad, inseguridad y miedos. Una trilogía para pensar la ciudad contemporánea. Alteridades, 63-74.

Observatorio Nacional Ciudadano (2016). Reportes y estadísticas sobre seguridad, justicia y legalidad en México. Recuperado em marzo de 2016 de: http:/ / onc.org.mx/

Sabatini, F., Worlmard, G., Rasse, A. y Trebilcock, M. (ed.) (2013). Cultura de cohesión e integración social en ciudades chilenas. Santiago de Chile: Instituto de Estudios Urbanos y Territoriales.

Santos, G. (30 de julio de 2015). Itapuã soma 21 assassinatos este ano e violência assusta. Correio da Bahia. Recuperado en marzo de 2016 de http:/ / www.correio24horas.com.br/detalhe/noticia/itapua-soma-21-assassinatos-este-ano-e-violencia-assu sta/?cHash=dced39a082c15d4e75017637bd620b7b

Simmel, G. (1979). A metrópole e a vida mental. Em O. Velho, O Fenômeno Urbano. $4^{\circ} \mathrm{Ed}, 11-25$. Rio de Janeiro: Zahar Editores.

Souza, M. (2008). Fobópole: o medo generalizado e a militarização da questão urbana. Rio de Janeiro: Bertrand Brasil.

SSP-BA (2015) Secretaría de Seguridad Pública de Bahía. Recuperado en octubre de 2015 de: http:/ / ssp.ba.gov.br

Vargas, J. (2013). Pegan robos a usuarios del transporte público. Info7. Recuperado de: http:/ / www.info7.mx/a/noticia/378235

Virilio, P. (2012). The administration of fear. Los Angeles: Semiotext(e).

Wagner, W. (1998). Descrição, explicação e método na pesquisa das Representações Sociais. En: Guareshi, P. e Jovchelovitch, S. (org.). Textos em representações sociais. Petrópolis: Vozes.

Zócalo (24 de diciembre de 2014). Centro de Monterrey, ipeligro!: zona de miedo. Zócalo. Recuperado de: http://www.zocalo. com.mx/seccion/articulo/ centro-de-monterrey-peligro-zona-de-miedo-1419411441 